\title{
Applying Axiomatic Design to Engineer's Job Search Defining DP of abduction skills for FR of new product development
}

\author{
Masayuki $\mathrm{Nakao}^{1, *}$, and Kenji Iino ${ }^{2}$ \\ ${ }^{1}$ The University of Tokyo, Department of Engineering Synthesis, School of Engineering, Hongo 7-3-1, Bunkyo-ku, Tokyo 113-8656, \\ JAPAN \\ 2 SYDROSE LP, 475 N. 1st St., San Jose, CA95112, USA
}

\begin{abstract}
Japan completed its acquisition of western technologies in 1990, however, industries that emerged through the process are facing zero growth now. The industries now need $\mathrm{FR}_{1}$ : Develop new products, in addition to $\mathrm{FR}_{2}$ : Maintain conventional products. On the other hand, in hiring new graduates from universities, such skills of $\mathrm{DP}_{1}$ : Expertise knowledge in engineering, and $\mathrm{DP}_{2}$ : Basic academic and management skills (leadership, loyalty, communication skills, and so on) have been valued. Students, on the other hand, are judged by ambiguous variables like $\mathrm{PV}_{1}$ : School reputation and $\mathrm{PV}_{2}$ : Interview, and receive job offers a year before graduation. This process, when viewed as a design process, is clearly coupled with both $\mathrm{DP}_{1}$ and $\mathrm{DP}_{2}$ required for both $\mathrm{FR}_{1}$ and $\mathrm{FR}_{2}$. The two DPs are effective for $\mathrm{FR}_{2}$ and have been proved successful, however, $\mathrm{DP}_{1}$ alone sometimes fails to meet $\mathrm{FR}_{1}$. The situation led to requiring $\mathrm{DP}_{1}$ ': Abduction and demonstration skills to be judged by $\mathrm{PV}_{1}$ ': Joint research or internship, a hiring system close to the western style. FRs are then uncoupled and $\mathrm{DP}_{1}$ ' may allow finding a student suited for $\mathrm{FR}_{1}$, however, the universities are not ready to teach $\mathrm{DP}_{1}$ ' to the students.
\end{abstract}

\section{Introduction}

This paper shows the results of our experiment of applying Axiomatic Design to recruiting of engineering graduates from universities. The subjects were students in the Mechanical Engineering (ME) Department in the School of Engineering at the University of Tokyo, where the authors teach. The paper identifies Functional Requirements (FRs) for manufacturing businesses, sets the competencies looked for in engineers as Design Parameters (DPs), then the Process Variables (PVs) are the methods of selecting students with such competencies. With the design equation set so, Axiomatic Design allows us to evaluate the independence axiom [1].

Chapter 1 reviews the histories of Japanese manufacturing industries and the above ME department, and Chapter 2 explains the design equation of past

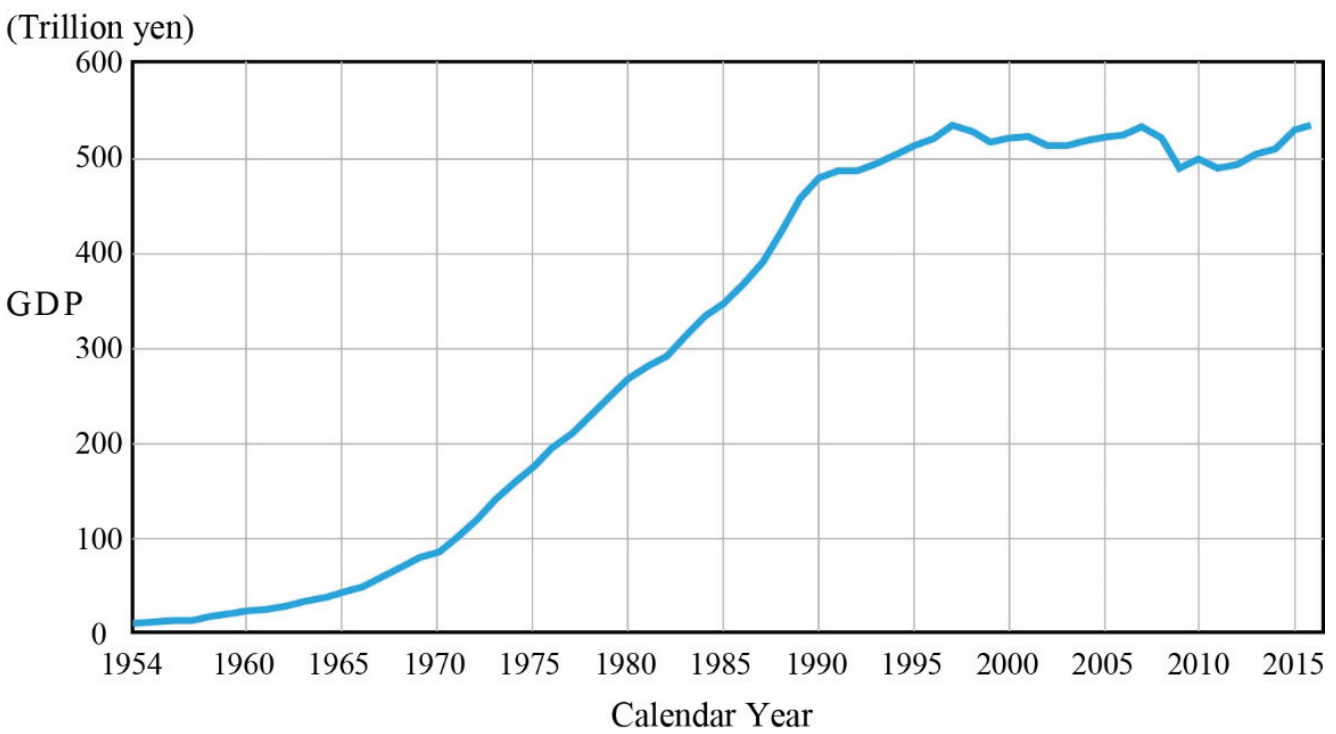

Fig. 1. Transition of Japan nominal GPD [http://www.esri.cao.go.jp/jp/sna/menu.html].

\footnotetext{
* Corresponding author: nakao@hnl.t.u-tokyo.ac.jp
} 
recruitment and their problems. Chapter 3 proposes a new design equation for recruiting graduating students in the future, and Chapter 4 discusses ideal education to meet the design equation and the problems. Chapter 5 summaries our work.

The University of Tokyo was established in 1877 when the Meiji Restoration that ended the Shogun era was complete and it is the leading University in Japan with 140 years of history to 2017. When it was established, the University educated its students to introduce western technology and domesticate the skills following the national slogan of "Enrich the state, strengthen the military." This driving force turned around and lost its effect in 1990.

Figure 1 shows the transition of Japan's Gross Domestic Product (GDP) in the post-World War II years since 1954 [2]. In 1945, immediately after the War, the Japanese GDP had tumbled down to about 1.5 trillion Japanese Yen (JPY), i.e., about US\$0.1 trillion at the current exchange rate. After the War, Japan entered its "economic miracle" years and its GDP kept growing to reach JPY500 trillion (US\$5 trillion). Just before 1990, however, the Japanese economy faced the "bubble burst" in real estate and stock markets. It was the beginning of Japan's zero-growth economy which has been around for 27 years still in this year 2017 .

Manufacturers like Sony, Toyota, Hitachi and so on had grown large at the time of 1990 and to alleviate the effects of higher JPY value and trade friction, they built factories and entered the market overseas. These corporations globalized and as of 2017, their domestic factories and employees consist only about $30 \%$ of their overall resources. In other words, they kept growing because their overseas markets grew, however, their domestic markets have been saturated and so are the Japanese businessmen.

Figure 2 shows where graduates from the $\mathrm{ME}$ Department have started working for during the 40 years of 1976 to 2016. The number of graduates have been about 100 to 150 annually summing Bachelor of Arts (BA) and Master of Science (MS) graduates. The vertical axis shows the graduate student counts with the upper positive half being those in manufacturing and the lower negative half non-manufacturing. The trend shows a turning point around 1990 .

During the 110 years before $1990,80 \%$ of the graduates started working in the manufacturing industry and the remaining $20 \%$ in non-manufacturing like, electric power, railway service, the central government and so on. Around 1984, the ratio of students starting in manufacturing started to drop to reach only $44(42 \%)$ in 1990. At the time, the drop in manufacturing recruits raised the number in non-manufacturing like finance (banking and security), trading, investment, and consulting.

The trend, however, did not last long with the burst of bubble economy and the recruits starting with manufacturing rose back to $70(65 \%)$. Around this time, however, favored industries shifted from material (steel and mining) and heavy industry (nuclear, electrical, automobile, train building) to IT machinery of computers, magnetic discs, liquid crystal displays, semiconductors, optical fibers, and so on.

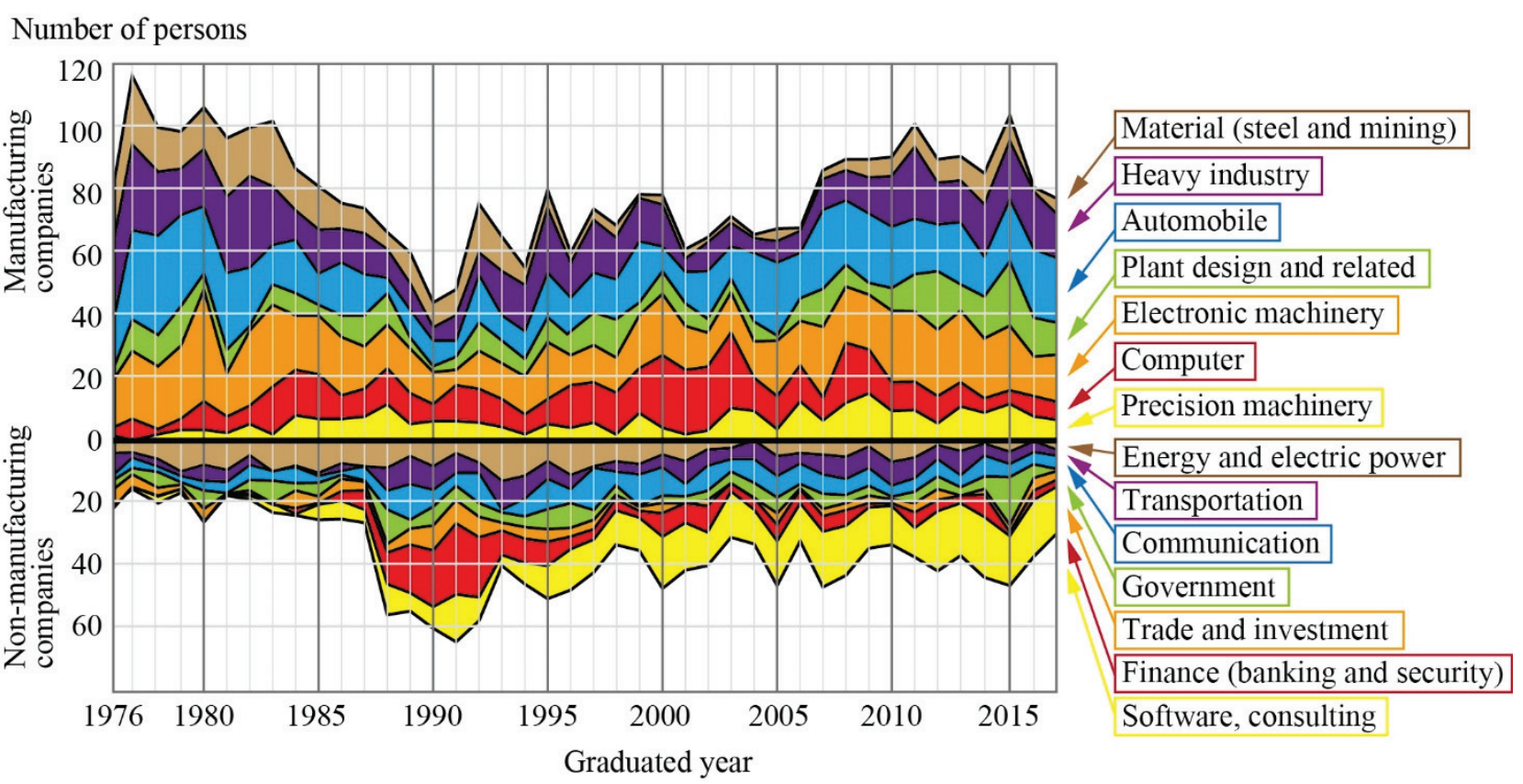

Fig. 2. History of employers of the University of Tokyo ME department graduates (1976-2017). 


$$
\begin{aligned}
& \left\{\begin{array}{l}
\mathrm{FR}_{1} \text { : Develop new products } \\
\mathrm{FR}_{2} \text { : Maintain conventional products }
\end{array}\right\} \\
& =\left[\begin{array}{ll}
\mathrm{X}_{11} & \mathrm{x}_{12} \\
-\mathrm{x}_{21} & \mathrm{X}_{22}
\end{array}\right]\left\{\begin{array}{l}
\mathrm{DP}_{1} \text { : Expertise knowledge in engineering } \\
\mathrm{DP}_{2} \text { : Basic academic and management skills }
\end{array}\right\} \\
& \left\{\begin{array}{l}
\mathrm{DP}_{1} \\
\mathrm{DP}_{2}
\end{array}\right\}=\left[\begin{array}{ll}
\mathrm{y}_{11} & \mathrm{y}_{21} \\
\mathrm{y}_{21} & \mathrm{y}_{22}
\end{array}\right]\left\{\begin{array}{l}
\mathrm{PV}_{1} \text { : School reputation } \\
\mathrm{PV}_{2} \text { : Interview }
\end{array}\right\} \\
& \left\{\mathrm{C}_{1} \text { : Minimize cost and time for recruiting }\right\}=\left[\begin{array}{ll}
\mathrm{Z}_{1} & \mathrm{Z}_{2}
\end{array}\right]\left\{\begin{array}{l}
\mathrm{PV}_{1} \\
\mathrm{PV}_{2}
\end{array}\right\}
\end{aligned}
$$

Fig. 3. Conventional design equation for recruiting engineering graduates.

Later in 2002, at the time of the so-called IT bubble burst, IT machinery industries sharply lost their popularity and the heavy industries and transportation equipment building regained their attractions. Further, the 2011 Great East Japan Earthquake caused industries like nuclear, semi-conductor, and cellular phones to drop almost to zero and in turn, automobile, batteries, and power electronics enjoyed increase of new hires.

The university faced its turning point in 2004, when it changed from a national institute to a national university corporation with the same faculty and administrative staff. The employees were freed from the detailed national institute rules, however, it was the starting point of having to earn their own operational funds. The Graduate School of Engineering, up to 2004, annually received JPY10 billion from the national budget to cover its administrative cost (labor and education), and additional JPY3 billion from the government and private companies for research. After the reformation, however, with no increase in the administration budget, its research expense skyrocketed to about JPY15 billion, i.e., 5 times. The research fund hired young researchers and the number of papers increased. The QS world ranking ranks our department at number 8 in Mechanical, Aeronautical \& Manufacturing Engineering [3].

The education program, on the other hand, hardly has made any changes in the basic mechanics lectures since the school hired Charles West in 1877 who introduced the western style mechanical engineering curriculum. The hands-on courses, on the other hand as we will introduce in Section 4, gradually made some changes since 2000, from projects that follow design cases in the west to projects that have the students produce something new on their own.

\section{Conventional design equation for recruitment}

Companies in the manufacturing business are always after growth and maintaining selling existing products are insufficient for survival. They have to continuously develop future products as an FR. Figure 3 shows the requirements for these businesses; $\mathrm{FR}_{1}$ : Develop new products, and $\mathrm{FR}_{2}$ : Maintain conventional products.
FR and DP in the figure relate as follows:

For $\mathrm{FR}_{1}$ of new product development, companies acquire technology from western countries or develop their own new ones. For such development, $\mathrm{DP}_{1}$ : Expertise knowledge in engineering is required. On the other hand, conventional products in $\mathrm{FR}_{2}$ have already won the trust from the customers, thus, engineers are required to keep implementing small improvements without making any large leaps and only $\mathrm{DP}_{2}$ : Basic academic and management skills (leadership, loyalty, communication, and so on) in sales and maintenance are sufficient.

Next about the interfering components in the design matrix. First, $\mathrm{x}_{12}$ is the effect of $\mathrm{DP}_{2}$ on $\mathrm{FR}_{1}$. The basic skills of $\mathrm{DP}_{2}$ alone cannot develop new products, however, it can support the development team to shorten the development time, thus, is has small contribution $\mathrm{x}_{12}$ with the small $\mathrm{x}$. The component $\mathrm{x}_{21}$ is the effect of $\mathrm{DP}_{1}$ on $\mathrm{FR}_{2}$, that the distinguished skills of $\mathrm{DP}_{1}$ may venture to make big modifications on stable products $\mathrm{FR}_{2}$ and cause a major drawback that can threaten the entire company, thus it has a negative sign with a small $\mathrm{x},-\mathrm{x}_{21}$. The interferences are non-zeros, i.e., the design is coupled.

Also, as Figure 1 showed, Japan has made zero growth throughout these 27 years, and the sole reason is because there were not enough new products of $\mathrm{FR}_{1}$. The expertise knowledge of DP1 cannot produce new innovative products and the $\mathrm{X}_{11}$ component in the design matrix was small. In general knowledge of mechanics and physics in $\mathrm{DP}_{1}$ are effective for analysis, however, is not effective for synthesis. A different set of skills specialized for design were in need.

Next are the relations among DPs and PVs.

The human resources (HR) departments at major corporations in Japan make once a year recruitment of large numbers of engineers needed for the next fiscal year (starting in April in Japan) from universities. The system is quite different from western companies where managers hire the necessary number of people in their groups when necessary. Japanese companies like Sony, Toyota, and Hitachi start their search in March of 2017 to hire engineers to start working in April of 2018 and conduct interviews by June to narrow down the candidates to about 200 to 400 to employ. 


$$
\begin{aligned}
& \left\{\begin{array}{l}
\mathrm{FR}_{1} \text { : Develop new products } \\
\mathrm{FR}_{2} \text { : Maintain conventional products }
\end{array}\right\} \\
& =\left[\begin{array}{cc}
\mathrm{X}_{11} & 0 \\
0 & \mathrm{X}_{22}
\end{array}\right]\left\{\begin{array}{l}
\mathrm{DP}_{1}^{\prime}: \text { Abduction and demonstration skills } \\
\mathrm{DP}_{2}: \text { Basic academic and management skills }
\end{array}\right\} \\
& \left\{\begin{array}{l}
\mathrm{DP}_{1}^{\prime} \\
\mathrm{DP}_{2}
\end{array}\right\}=\left[\begin{array}{cc}
\mathrm{Y}_{11} & 0 \\
0 & \mathrm{Y}_{22}
\end{array}\right]\left\{\begin{array}{l}
\mathrm{PV}_{1}^{\prime}: \text { Joint research or internship } \\
\mathrm{PV}_{2}: \text { Interview }
\end{array}\right\} \\
& \left\{\mathrm{C}_{1}^{\prime}: \text { Minimize cost and time for development }\right\}=\left[\begin{array}{ll}
\mathrm{Z}_{1} & 0
\end{array}\right]\left\{\begin{array}{l}
\mathrm{DP}_{1}^{\prime} \\
\mathrm{DP}_{2}
\end{array}\right\}
\end{aligned}
$$

Figure 4. New design equation for recruiting engineering graduates.

Since the HR departments have to complete the search in such a short period, they do not carry out written examinations and base their judgement on $\mathrm{PV}_{1}$ : School reputation, to evaluate $\mathrm{DP}_{1}$ : Expertise knowledge in engineering. In other words, they preliminarily hire the planned number of students based on recommendations from professors. $\mathrm{DP}_{2}$ : Basic academic and management skills are also evaluated with impressions gained through short 30 minute to 1 hour interviews $\left(\mathrm{PV}_{2}\right)$. The HR departments adopted PVs in Figure 3 because they satisfied the constraint $C_{1}$ : Minimize cost and time for recruiting.

Such recruitment proceeds in ambiguous reputations and impressions, thus the components $\mathrm{y}_{11}, \mathrm{y}_{12}, \mathrm{y}_{21}$, and $\mathrm{y}_{22}$ all make unclear effects on the DPs. Sociologist Hattori proved this fuzziness and his book [4] was a best seller in 2017. Substituting DP in the lower equation into the upper equation shows that the design equation that relates PV to FR gives a coupled design. In other words, hiring students from well-known universities after interviews does not necessarily heighten the odds for accomplishing the FRs.

\section{Design equation for future recruitment}

As the earlier sections explained, the design equation for recruitment in Figure 3 is not a good strategy for developing new products or markets. Both the industries and universities had such suspicions. Figure 4 shows our new proposal as the design equation for recruitment. Differences with Figure 3 are in $\mathrm{DP}_{1}, \mathrm{PV}_{1}$, and $\mathrm{C}_{1}$.

First, the skills needed for developing new products are changed to $\mathrm{DP}_{1}$ ': Abduction and demonstration skills. They are the same as efforts in validating a hypothesis which is the basic concept of science. Abduction is the skills in identifying a set of FRs and DPs for a new product in a short time without induction or deduction. Engineers in general, however, dislike illogical and reckless abduction. In actual design, copying someone else's design is accepted in the business world as long as the royalty is paid, thus the designers do not go after new inventions. When designs are worked into products, the reliability is a large factor, therefore, designers tend to use parts with proven track of trouble free uses instead of trying newly invented parts.
A good abduction is, of course, backed by expertise knowledge $\left(\mathrm{DP}_{1}\right)$ and that by a skilled engineer is not unscientific. Abduction, however, does not automatically come out from the brain by pouring expert knowledge into it. Producing abduction takes a separate education explained in the following section.

Next, our proposed design equation changes $\mathrm{PV}_{1}$ to evaluate the skills for the new $\mathrm{DP}_{1}$ '. The $\mathrm{PV}$ is $\mathrm{PV}_{1}$ ': Joint research and internship. A joint research lasts for a long period of a year or longer whereas an internship is a month or more of work experience for a student. This variable is not suited for the above $C_{1}$ of minimizing the cost and time for recruitment. Needless to say, however, working together with the employment candidate for an extended time is more effective in evaluating the skills compared to an hour of interview. This method is in practice for candidates of senior engineers in the western world and Japanese trading companies and consulting industries have started experimenting with the method for executive candidates that make about $20 \%$ of the entire recruits.

Lastly about constraints, the above $\mathrm{C}_{1}$ is replaced with our proposed $\mathrm{C}_{1}$ ': Minimize cost and time for development. Of course, the cost covers the recruiting cost, however, some expense in recruiting would be tolerable because hiring an unfit engineer can lead to failure and business loss.

For the design equation, $\mathrm{DP}_{1}{ }^{\prime}$ : Abduction and demonstration corresponds to $\mathrm{FR}_{1}$ : New products and $\mathrm{DP}_{2}$ : Basic academic and management skills to $\mathrm{FR}_{2}$ : Conventional products; both relations are independent. Also the long but accurate $\mathrm{PV}_{1}$ ': Internship would correspond to $\mathrm{DP}_{1}$ ', and the short but inexpensive $\mathrm{PV}_{2}$ : Interview to $\mathrm{DP}_{2}$; also independent correspondences. The design equation shows an uncoupled design and $\mathrm{FR}_{1}$ ' will succeed with high probability.

Developing human resources in 2 groups may pose a concern that members of the two teams can turn uniform and lack energy, however, a company that adopted this method of recruitment have identified a resource with both $\mathrm{DP}_{1}$ ' and $\mathrm{DP}_{2}$ qualifications who has been promoted as an executive candidate. 


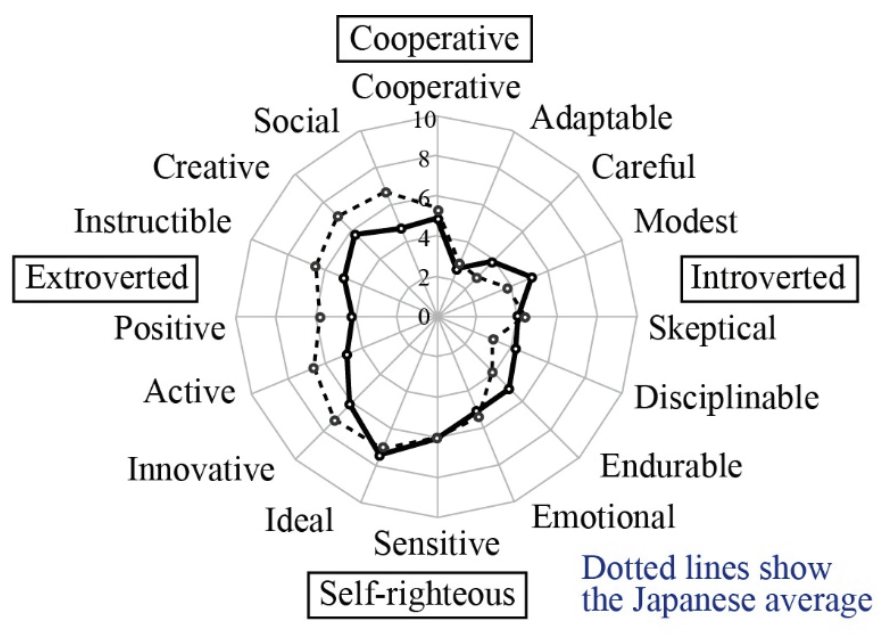

(a) Personality: Students are more introverted

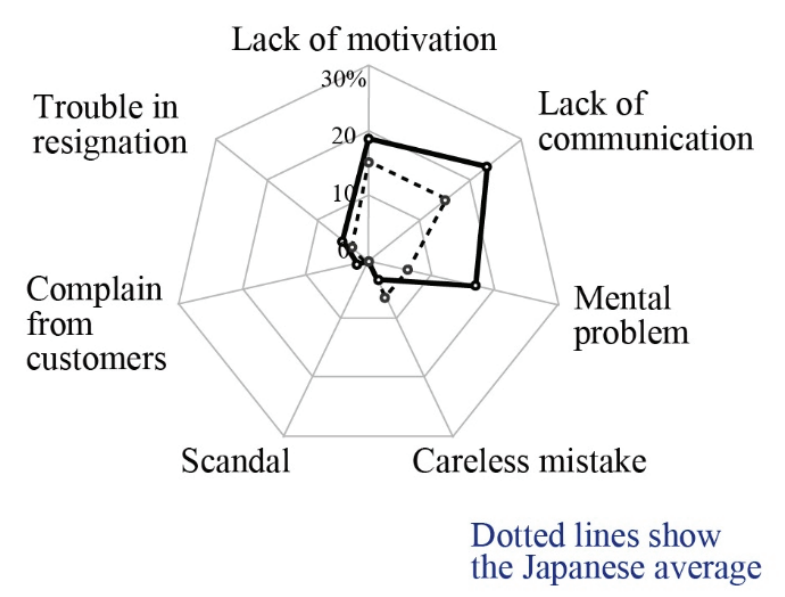

(c) Risk to employer: Students pose large risk to employment.

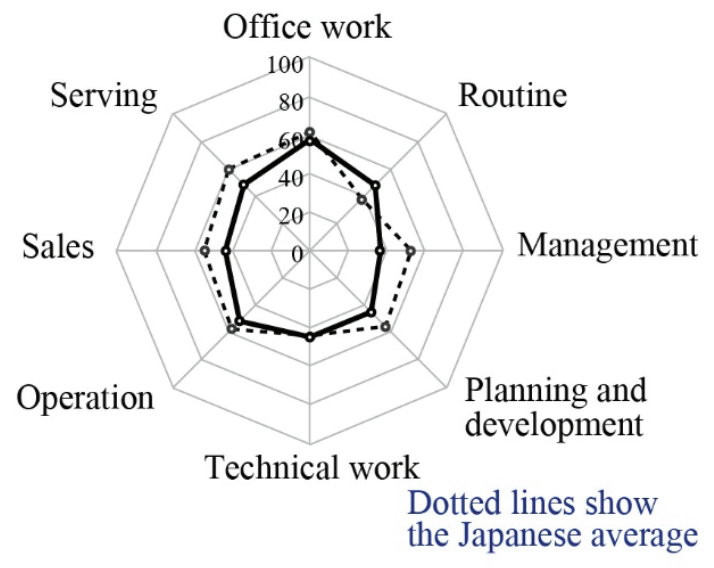

(b) Suitable jobs: Students suit routine work.

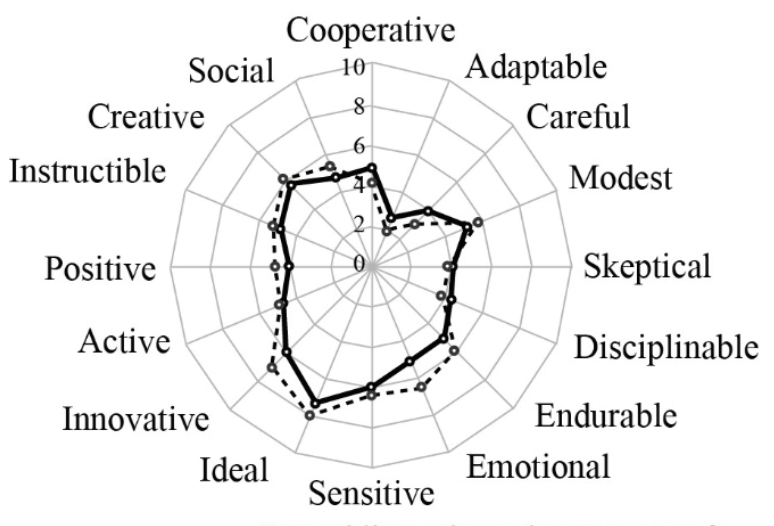

Dotted lines show the average of academic-track high school students

(d) Personality is similar with high school students

Fig. 5. Personality radar chart of the University of Tokyo ME students (solid line)

\section{Education to realize the new design equation for recruitment and its issues}

The authors started joint research projects at JPY40 million (about US\$0.4 million) a year per company since 2006 after our university turned into a corporation. Part of the purpose was to select students suited for $\mathrm{DP}_{1}$ ' in the above design equation for recruitment in Figure 4. Our research lab carries out research in manufacturing technology with Komatsu, Toyota, Asahi Glass, Mitsubishi Heavy Industry, Sony, and so on. Bill Gates have also made a donation to conduct research in Internet of Things (IoT). When students participating in these joint research projects are identified with high skills of abduction, they often join the company after graduation.

Also, educational courses to actively train such resources started since about the year 2000. They are exercises to find their own design solutions from abduction. Junior students go through exercises every afternoon; In the spring/summer semester, groups of 4 design and fabricate free-style Stirling engines; In the fall/winter semester the students design and produce their own ideas of robots or games using mechatronics in duos. In the first year of graduate studies, a Projectbased learning class has corporate sponsors set FRs and the students find DPs on their own. In this course, the students put their $\mathrm{DP}_{1}$ ': Abduction and demonstration skills in practice and for their Bachelor's or Master's degrees, the students have to challenge research projects with novelty and innovation.

There have been no design methodology that explain how to gain skills in abduction. Axiomatic Design is no exception. The general trend, however, is if one, even with limitations in basic knowledge, tries out with courage, abduction skills start to come to life.

Personal observation, on the other hand, finds some students that totally lack that courage to venture and that is the biggest problem. Figure 5 shows the results of a personality questionnaire (by Net \& ASKs), with 144 Yes/No type questions, we conduct each year with the above ME department students [5]. As (a) shows, the students were more introverted than the average 3 million Japanese. The results also showed that these students better suit routine work compared to the Japanese average (b). Without any mistakes, they can repeat the routine work consistently. Our ideal 
expectation is that they would suit technical, planning, or management work to lead manufacturing companies, however, their introversion lacked the power to lead people.

(c) shows risks to the employers. Some of the students are so introverted that they lack communication skills and their possibility of facing mental problems was twice the national average. Among the job hunting students to start working in April 2017, there were 10 that had not yet received official job offers by September 2016 , i.e., 6 months into their job hunting. That is very rare for students at the University of Tokyo. Six of the 10 students $(60 \%)$ had received strong warnings of possible mental problems, a warning that is only given to $3 \%$ of the average Japanese. (d) compares the university students' personality distribution with that of academictrack high schools. The striking resemblance is clear. To put it in a clear way, the Japanese educational system that determines who enters universities based only on entrance examinations, that tests the students' skills in memory, gather introverted students that are good at routine work as elites to the University of Tokyo.

Forming teams of introverted students and having them polish up their abduction skills, unrelated to power of memory, are hard work for the faculty. The instructors have to challenge projects not found in textbooks nor google. Ever since they were at grade schools the students have taken the strategy of starting from easy to solve problems and developing their skills in tackling problems that are more complex but with known solutions. They have a hard time selecting DPs that they are not sure if they can be realized.

The questionnaire results after the above exercise courses told us that students point to encouragement from instructors and teaching assistants during consultation as keys to successful completion. Once they are given the courage, students with lots of specialized technical knowledge can make abductions. The authors instruct young instructors when they are approached by puzzled students, not to teach them the solutions but to provide coaching to guide their thinking. It may be the slow way in terms of efficiency, however, for design education in Japan, it is important to have the students learn to think for themselves without knowing the solutions.

\section{Summary}

This paper expressed the system of recruiting fresh engineers in Japan with a design equation in Axiomatic Design. The formulation set corporate goals to $\mathrm{FR}_{1}$ : Develop new products, and $\mathrm{FR}_{2}$ : Maintain conventional products. In the past, human resource skills to accomplish them had been set to $\mathrm{DP}_{1}$ : Expertise knowledge in engineering, and $\mathrm{DP}_{2}$ : Basic academic and management skills. Furthermore, the selection of students were based on $\mathrm{PV}_{1}$ : School reputation, and $\mathrm{PV}_{2}$ : Interview. Japan in the zero-growth period after 1990 can no longer just copy western technology and has to start developing its own new products, thus, these $\mathrm{DP}_{1}$ and $\mathrm{FR}_{1}$ turned no longer effective in meeting the goals. The FRs and DPs were both coupled designs with low probability of success, and furthermore, the fuzzy $\mathrm{PV}_{1}$ was ineffective in hiring human resources with the capability of developing new products $\mathrm{DP}_{1}$.

The authors proposed setting $\mathrm{DP}_{1}{ }^{\prime}$ : Abduction and demonstration skills in place of $\mathrm{DP}_{1}$, and $\mathrm{PV}_{1}$ ': Joint research or internship in place of $\mathrm{PV}_{1}$. These replacements turn the design equation an uncoupled one to increase the probability of meeting FRs and DPs. The authors carried out $\mathrm{PV}_{1}$ ': Joint researches to identify students with $\mathrm{DP}_{1}$ ': Adduction. In addition since about 2000, we have developed exercise courses to enhance the students' abduction skills that have the student come up with their own DPs. The largest problem found was that some students are satisfied with their studies of passive written tests and lack the courage to actively challenge new abductions.

\section{References}

1. N.P. Suh, Axiomatic Design: Advanced Application, Oxford University Press (2001)

2. Cabinet Office, Government of Japan, Gross Domestic Product Statistics, http://www.esri.cao.go.jp/jp/sna/menu.html

3. QS Quacquarelli Symonds Limited, QS World University Rankings by Subject, https://www. topuniversities.com/subject-rankings/2017

4. Y. Hattori, Study of selecting, Shinchosha (2016)

5. M. Nakao et al., Mind wandering, brain training to acquire values from cobwebs, Nikkan Kogyo Shimbun (2017) 